\title{
ESPÉCIES EXÓTICAS INVASORAS NA ARBORIZAÇÃO URBANA DE VIAS PÚBLICAS DE SANANDUVA/RS
}

\author{
INVASIVE ALIEN SPECIES IN URBAN AFFORESTATION OF PUBLIC ROADS IN \\ SANANDUVA, RS
}

\author{
Rosele Clairete dos Santos ${ }^{1}$, Luciano Antunes², Douglas Bessegatto ${ }^{3}$
}

\begin{abstract}
RESUMO
O presente trabalho objetivou analisar quali-quantitativamente as espécies exóticas invasoras presentes na arborização urbana das vias públicas do centro da cidade de Sananduva/RS. Os critérios adotados foram à estimativa quali-quantitativa das árvores e a origem das espécies (nativas, exóticas e exóticas invasoras). O levantamento dos dados realizou-se no período de agosto a dezembro de 2015, através de visitas "in loco" às ruas e avenidas e o levantamento da arborização pelo método de inventário qualiquantitativo do tipo censo, considerando todos os indivíduos vegetais de porte arbóreo e arbustivo, existentes em 16 ruas e 5 avenidas do bairro Centro do município de Sananduva/RS, através de observação direta, anotações e registro fotográfico. Na área pesquisada constatou-se um total de 517 indivíduos vegetais, entre arbóreos e arbustivos, distribuídos em 36 gêneros, 21 famílias e 43 espécies, sendo sete indivíduos não identificados (ausência de características botânicas - podas drásticas). Aproximadamente $57 \%$ das espécies existentes nas vias estudadas tem origem exótica, destes $24,6 \%$ são classificados como invasoras. Para que mudanças consideráveis aconteçam é imprescindível o uso de uma abordagem diferenciada no planejamento arbóreo-urbano de Sananduva/RS, com base em critérios técnico-científicos para o estabelecimento de uma arborização urbana voltada ao emprego de espécies nativas da região juntamente com a substituição gradativa das espécies exóticas, no propósito de beneficiar a biodiversidade e ecossistemas naturais.
\end{abstract}

Palavras-chave: Inventário; Urbanização; Gestão ambiental; Planejamento.

\section{ABSTRACT}

This research aims to analyze qualitatively and quantitatively the invasive alien species present in urban afforestation on public roads in the city center of Sananduva, RS. The adopted criteria were the qualitative and quantitative estimation of trees and the origin of these same species (native, alien, and invasive alien). The data collection was conducted between August and December, 2015, by in loco visitations to the streets and avenues. While the data inventory was gathered by a census, considering all arboreal and shrub individuals existing in 16 streets and 5 avenues of Centro neighborhood of Sananduva/RS, through direct observation and photographic registration. In the researched area, we found a total of 517 vegetal individuals, including arboreal and shrub elements, distributed in 21 botanical families and 43 species. Almost $57 \%$ of the existing species from the analyzed roads present alien origin; being $24,6 \%$ classified as invasive. In order to occur considerable changes, it a distinguished approach to arboreal-urban planning in Sananduva, RS, is essential. Which should be based on scientific and technical criteria to the implementation of an urban afforestation oriented to the use of species native from the region, along with the gradual replacement of alien individuals, with the purpose of benefiting natural biodiversity and ecosystems.

Keywords: Inventory; Urbanization; Environmental Management; Planning.

Recebido em 13.01.2017 e aceito em 10.04.2017

1 Bióloga, Especialista em Licenciamento Ambiental, Mestre e Doutora em Ciência do Solo. Professora Adjunta de Ciências Biológicas Universidade Estadual do Rio Grande do Sul. Sananduva/RS. E-mail: rosele-santos@uergs.edu.br

2 Acadêmico do Curso de Bacharelado em Gestão Ambiental. Universidade Estadual do Rio Grande do Sul. Sananduva/RS. E-mail: luciano-antunes@uergs.edu.br

3 Acadêmico do Curso de Bacharelado em Gestão Ambiental. Universidade Estadual do Rio Grande do Sul. Sananduva/RS. E-mail: douglas-bessegatto@uergs.edu.br 


\section{INTRODUÇÃO}

A arborização urbana é o conjunto de áreas públicas ou privadas com vegetação predominantemente arbórea ou em estado natural que uma cidade apresenta, incluindo as árvores das ruas, avenidas, parques públicos e demais áreas verdes (DORIGON; PAGLIARI, 2013).

A arborização exerce função importante nos centros urbanos, sendo responsável por uma série de benefícios ambientais e sociais que melhoram a qualidade de vida nas cidades e a saúde física e mental da população (RIBEIRO, 2009).

O início da arborização urbana deu-se muito distante do Brasil, em épocas remotas. A inclusão consciente de árvores nos espaços públicos das cidades aconteceu primeiro na Europa no decorrer do século XVII (ANDRADE, 2002). O mesmo autor cita que no Brasil a arborização desenvolveu-se pouco depois do paisagismo, como forma de herança dos países que já utilizavam essa prática. De acordo com Matos e Queiroz (2009) foi na época do Brasil colônia que as espécies exóticas começaram a ser introduzidas no país, trazidas da Europa para aproximar a paisagem brasileira com as terras europeias. Sendo essa uma das primeiras experiências voltadas à arborização urbana no país.

Segundo Andrade (2002), no fim do século XIX, o conceito de parques e ruas arborizadas estava amplamente assimilado. A árvore tornou-se um símbolo de civilidade, de cultura e de patriotismo.

Para Ribeiro (2009), a arborização urbana passou a ser vista nas cidades como importante elemento natural reestruturador do espaço urbano, pois aproxima as condições ambientais normais da relação com o meio urbano.

Simultaneamente ao crescimento da arborização dos centros urbanos, ocorreu um intenso emprego de plantas de diferentes origens. Essas plantas exóticas podem ter algumas vantagens, como crescimento rápido e vigor, mas essas características podem caracterizar a espécie o hábito invasor. Afetando o desenvolvimento das espécies nativas, uma vez que compete com as mesmas por água, luz e nutrientes (MATOS; QUEIROZ, 2009).

Considerando-se as definições adotadas pela Convenção Internacional sobre Diversidade Biológica (CDB, 1992) na 6ª Conferência das Partes (CDB COP-6, Decisão VI/23, 2002), uma espécie é exótica (ou introduzida) quando situada em um local diferente do de sua distribuição natural, ocasionada pela introdução humana, de forma voluntária ou involuntária. Se a espécie introduzida se reproduzir e gerar descendentes férteis, com alta probabilidade de sobreviver no novo hábitat, ela é considerada estabelecida. Caso a espécie estabelecida expanda sua distribuição no novo hábitat, ameaçando a biodiversidade nativa, ela passa a ser considerada uma espécie exótica invasora (CDB, 1992). 
Estudos apontam que espécies exóticas invasoras são implantadas na arborização de vias públicas, parques, bosques e praças, principalmente pelo desconhecimento das normas e da legislação existente, sabe-se que a eficiência da arborização urbana depende exclusivamente do seu planejamento. Assim, planejar é fazer o uso de critérios técnico-científicos para o estabelecimento da arborização nos estágios de curto, médio e longo prazo são ações necessárias para a implantação de uma arborização predominantemente nativa e bem planejada (HOPPEN et al. 2014).

Embasado nesses aspectos, o presente trabalho tem por objetivo analisar qualiquantitativamente as espécies exóticas invasoras presentes na arborização urbana das vias públicas do centro da cidade de Sananduva/RS.

\section{MATERIAL E MÉTODOS}

A área de estudo está situada na região rio-grandense conhecida como Campos de Cima da Serra, nordeste do estado, com as coordenadas $27^{\circ} 56^{\prime} 59^{\prime \prime}$ S e 5148'24" W e altitude média de 636 m. O município de Sananduva abrange uma área de 504,549 km², possuindo uma população de 15.373 habitantes (IBGE, 2010).

O município está sob o domínio do bioma Mata Atlântica, sendo sua cobertura vegetal caracterizada por atividades agrárias e vegetações secundárias do tipo Floresta Ombrófila Mista -Mata de Araucárias- (IBGE, 2010).

A metodologia empregada consistiu, no levantamento da arborização pelo método de inventário quali-quantitativo do tipo censo, considerando todos os indivíduos vegetais de porte arbóreo e arbustivo, existentes em 16 ruas e 5 avenidas do bairro Centro do município de Sananduva/RS, através de observação direta, anotações e registro fotográfico.

As áreas foram selecionadas devido ao fato das vias serem os principais pontos de acesso à cidade, além de haver grande circulação de pessoas e o trânsito ser mais intenso, quando comparado às demais vias urbanas. Para a identificação das espécies botânicas coletadas foi utilizada literatura especializada e formulários específicos (MELO et al., 2007) foram preenchidos considerando variáveis quantitativas ou categóricas, como: aspectos biológicos (identificação taxonômica), origem do espécime (exótica, exótica invasora ou nativa) e condições fitossanitárias (podas drásticas e conflito com calçada e fiação elétrica).

Todos os indivíduos foram analisados, fotografados e identificados taxonomicamente, com auxílio de chaves dicotômicas.

A frequência relativa das espécies no estudo (\%) foi obtida através da razão entre o número de indivíduos da espécie e o número total de indivíduos no estudo (BLUM et al., 2008). 
As visitas para coleta de dados ocorreram durante os meses de agosto a dezembro de 2015. Com base nos dados levantados, foi calculada a porcentagem de cada espécie ocorrente na área de estudo através do programa Microsoft Office Excel 2010.

Com base no levantamento de campo, foi realizada a análise da composição da arborização com a definição das espécies quanto a origem: nativas (planta que é natural, própria da região em que vive, ou seja, que cresce dentro dos seus limites naturais incluindo a sua área potencial de dispersão (IAP, 2017)), exóticas (espécies que não ocorre espontaneamente nos ecossistemas existentes em território brasileiro, sendo oriunda de ecossistemas de outros países) e exóticas invasoras no Brasil (HORUS INSTITUTE, 2017).

\section{RESULTADOS E DISCUSSÃO}

Nas áreas pesquisadas constatou-se um total de 517 indivíduos vegetais, entre arbóreos e arbustivos, distribuídos em 36 gêneros, 21 famílias e 43 espécies, sendo sete indivíduos não identificados (ausência de características botânicas - podas drásticas) (Tabela 1).

Observando-se os dados apresentados na Tabela 1, o número de espécies exóticas (57\%) supera o de espécies nativas (43\%). Já, as espécies exóticas invasoras, compõem $24,6 \%$ de toda a composição da arborização urbana da área estudada, distribuídas em 10 espécies. As famílias mais abundantes em espécies foram: Myrtaceae (25\%), Bignoniaceae $(9,1 \%)$ e Lauraceae (6,8\%). Em estudo realizado em Tuparendi-RS, Motter (2012) também descreve que foi encontrado representatividade de espécies nas famílias citadas. Já Boeni e Silveira (2011), em Porto Alegre-RS, encontraram maior representatividade nas famílias Fabaceae, Myrtaceae e Arecaceae. Dall Aqua e Müller (2014), em estudo realizado em Santa Rosa/RS também descreveram representatividade das famílias Myrtaceae e Bignoniaceae.

Dentre as espécies exóticas encontradas, as que tiveram maior ocorrência foram: Lagerstroemia indica com 88 indivíduos (19,34\%), Cupresses lusitanica com 48 indivíduos (9,28\%), Citrus sp. com 35 indivíduos (6,77\%), Ligustrum lucidum com 32 indivíduos (6,19\%) e Cinnamomum burmannii com 25 indivíduos (4,83\%), representando mais de $46 \%$ da composição arbórea urbana da área estudada, sendo destas, o Cupresses Iusitanica (9,28\%), o Ligustrum lucidum (6,19\%) e o Cinnamomum burmannii (4,83\%) consideradas exóticas invasoras pelo Instituto Horus (2017). Os espécimes descritos como exóticos invasores pelo Instituto Horus (2017), foram georreferenciados e encontram-se demarcados no mapa (Figura 1). 
Tabela 1. Espécies encontradas na Arborização Urbana de vias públicas da cidade de Sananduva-RS (NI: número de indivíduos; Pr: Procedência e FrR: Frequência Relativa).

Table 1. Species found in the Urban Afforestation of public roads of the city of Sananduva-RS (NI: number of individuals; Pr: Origin, and FrR: Relative Frequency).

\begin{tabular}{|c|c|c|c|c|c|}
\hline Família & Nome popular & Nome Científico & NI. & FrR. & Pr. \\
\hline ANACARDIACEAE & $\begin{array}{l}\text { Aroeira salsa } \\
\text { Aroeira vermelha }\end{array}$ & $\begin{array}{l}\text { Schinus molle L. } \\
\text { Schinus terebinthifolius Raddi }\end{array}$ & $\begin{array}{l}25 \\
1\end{array}$ & $\begin{array}{l}4,8 \\
0,2\end{array}$ & $\begin{array}{l}\text { Nativa } \\
\text { Nativa }\end{array}$ \\
\hline APOCYNACEAE & $\begin{array}{l}\text { Oleandro } \\
\text { Butiá }\end{array}$ & $\begin{array}{l}\text { Nerium oleander } \\
\text { Syagrus coronata }\end{array}$ & $\begin{array}{l}6 \\
7 \\
\end{array}$ & $\begin{array}{l}1,2 \\
1,4\end{array}$ & $\begin{array}{l}\text { Exótica } \\
\text { Nativa }\end{array}$ \\
\hline ARECACEAE & Jerivá & $\begin{array}{l}\text { Syagrus romanzoffiana } \\
\text { (Cham.) Glassman }\end{array}$ & 12 & 2,3 & Nativa \\
\hline BIGNONIACEAE & $\begin{array}{l}\text { Ipê } \\
\text { Ipê amarelo } \\
\text { Ipê rosa } \\
\text { Jacarandá mimoso } \\
\end{array}$ & $\begin{array}{l}\text { Handroanthus sp. } \\
\text { Handroanthus albus } \\
\text { Handroanthus heptaphyllus } \\
\text { Jacaranda mimosaefolia }\end{array}$ & $\begin{array}{l}5 \\
2 \\
1 \\
4 \\
\end{array}$ & $\begin{array}{l}1,0 \\
0,4 \\
0,2 \\
0,8 \\
\end{array}$ & $\begin{array}{l}\text { Nativa } \\
\text { Nativa } \\
\text { Nativa } \\
\text { Exótica } \\
\end{array}$ \\
\hline COMBRETACEAE & Sete capotes & Terminalia catappa L. & 1 & 0,2 & $\begin{array}{l}\text { Exótica } \\
\text { Invasora }\end{array}$ \\
\hline CUPRESSACEAE & Cipreste & Cupresses Iusitanica & 48 & 9,3 & $\begin{array}{l}\text { Exótica } \\
\text { Invasora }\end{array}$ \\
\hline FABACEAE & $\begin{array}{l}\text { Caliandra } \\
\text { Corticeira } \\
\text { Ingá }\end{array}$ & $\begin{array}{l}\text { Calliandra brevipes Benth. } \\
\text { Erythrina crista - galli L. } \\
\text { Inga sp. }\end{array}$ & $\begin{array}{l}2 \\
3 \\
2\end{array}$ & $\begin{array}{l}0,4 \\
0,6 \\
0,4\end{array}$ & $\begin{array}{l}\text { Exótica } \\
\text { Nativa } \\
\text { Nativa }\end{array}$ \\
\hline JUGLANDACEAE & Noz pecan & Carya illinoensis & 1 & 0,2 & Exótica \\
\hline \multirow[b]{2}{*}{ LAURACEAE } & $\begin{array}{l}\text { Abacateiro } \\
\text { Canela }\end{array}$ & $\begin{array}{l}\text { Persea americana Mill. } \\
\text { Nectandra sp. }\end{array}$ & $\begin{array}{l}2 \\
46\end{array}$ & $\begin{array}{l}0,4 \\
8,9\end{array}$ & $\begin{array}{l}\text { Exótica } \\
\text { Invasora } \\
\text { Nativa }\end{array}$ \\
\hline & Canela da indonésia & $\begin{array}{l}\text { Cinnamomum burmannii } \\
\text { (Nees \& Th. Nees) Nees ex } \\
\text { Blume }\end{array}$ & 25 & 4,8 & $\begin{array}{l}\text { Exótica } \\
\text { Invasora }\end{array}$ \\
\hline \multirow[t]{2}{*}{ LEGUMINOSAE } & Acácia mimosa & Acacia podalyriifolia & 1 & 0,2 & $\begin{array}{l}\text { Exótica } \\
\text { Invasora }\end{array}$ \\
\hline & Chuva de ouro & Cassia fistula L. & $\frac{5}{2}$ & $\frac{1,0}{04}$ & $\frac{\text { Exótica }}{\text { Nativa }}$ \\
\hline MELIACEAE & Cinamomo & Melia azedarach L. & 14 & 2,7 & $\begin{array}{l}\text { Exótica } \\
\text { Invasora }\end{array}$ \\
\hline MORACEAE & $\begin{array}{l}\text { Ficus benjamina } \\
\text { Figueira nativa }\end{array}$ & $\begin{array}{l}\text { Ficus benjamina } \\
\text { Ficus adhatodifolia Schott }\end{array}$ & $\begin{array}{l}3 \\
1 \\
\end{array}$ & $\begin{array}{l}0,6 \\
0,2\end{array}$ & $\begin{array}{l}\text { Exótica } \\
\text { Nativa }\end{array}$ \\
\hline \multirow{5}{*}{ MYRTACEAE } & $\begin{array}{l}\text { Araça } \\
\text { Cerejeira } \\
\text { Escova de garrafa } \\
\text { Goiaba serrana }\end{array}$ & $\begin{array}{l}\text { Psidium cattleianum } \\
\text { Eugenia sp. } \\
\text { Callistemon speciosus } \\
\text { Acca sellowiana }\end{array}$ & $\begin{array}{l}4 \\
10 \\
12 \\
2\end{array}$ & $\begin{array}{l}0,8 \\
1,9 \\
2,3 \\
0,4\end{array}$ & \multirow{5}{*}{$\begin{array}{l}\text { Nativa } \\
\text { Nativa } \\
\text { Exótica } \\
\text { Nativa } \\
\text { Exótica } \\
\text { Invasora } \\
\text { Nativa } \\
\text { Nativa } \\
\text { Nativa } \\
\text { Exótica } \\
\text { Invasora } \\
\text { Nativa } \\
\text { Nativa }\end{array}$} \\
\hline & Goiaba & Psidium guajava $L$. & 1 & 0,2 & \\
\hline & $\begin{array}{l}\text { Guabiju } \\
\text { Guabiroba } \\
\text { Jabuticaba }\end{array}$ & $\begin{array}{l}\text { Myrcianthes pungens } \\
\text { Campomanesia xanthocarpa } \\
\text { Pilinia peruviana }\end{array}$ & $\begin{array}{l}30 \\
2 \\
1\end{array}$ & $\begin{array}{l}5,8 \\
0,4 \\
0,2\end{array}$ & \\
\hline & Jambolão & Syzygium cuminni & 2 & 0,4 & \\
\hline & $\begin{array}{l}\text { Pitanga } \\
\text { Uvaia }\end{array}$ & $\begin{array}{l}\text { Eugenia uniflora L. } \\
\text { Eugenia uvalha Cambess. }\end{array}$ & $\begin{array}{l}52 \\
4 \\
\end{array}$ & $\begin{array}{l}10,1 \\
0,8\end{array}$ & \\
\hline NYCTAGINACEAE & Extremosa & Lagerstroemia indica L. & 88 & 17 & Exótica \\
\hline OLEACEAE & Ligustro & Ligustrum lucidum & 32 & 6,2 & $\begin{array}{l}\text { Exótica } \\
\text { Invasora }\end{array}$ \\
\hline PINACEAE & Pinheiro & Pinus sp. & 1 & 0,2 & $\begin{array}{l}\text { Exótica } \\
\text { Invasora }\end{array}$ \\
\hline ROSASEAE & $\begin{array}{l}\text { Pessegueiro } \\
\text { Ameixa }\end{array}$ & $\begin{array}{l}\text { Prunus persica } \\
\text { Prunus cerasifera Ehrl }\end{array}$ & $\begin{array}{l}1 \\
12 \\
\end{array}$ & $\begin{array}{l}0,2 \\
2,3\end{array}$ & $\begin{array}{l}\text { Exótica } \\
\text { Exótica }\end{array}$ \\
\hline RUTACEAE & Citrus & Citrus sp. & 35 & 6,8 & Exótica \\
\hline SAPINDACEAE & Chal-chal & Allophylus edulis & 1 & 0,2 & Nativa \\
\hline TEACEAE & Camélia & Camellia japonica & 1 & 0,2 & Exótica \\
\hline Não identificado & & - & 7 & 1,4 & \\
\hline Total & & & 517 & 100,0 & \\
\hline
\end{tabular}


Destaca-se que a rua João Vieira Neto apresentou um total de 35 espécimes sendo destes 30 espécimes exóticos (85\%) e a quantidade de espécimes exóticos invasores foi de 14 espécimes.

Figura 1. Demarcação dos espécimes exóticos invasores observados na arborização urbana de vias públicas de Sananduva/RS

Figure 1. Demarcation of invasive exotic specimens observed in the urban afforestation of public roads of Sananduva/RS

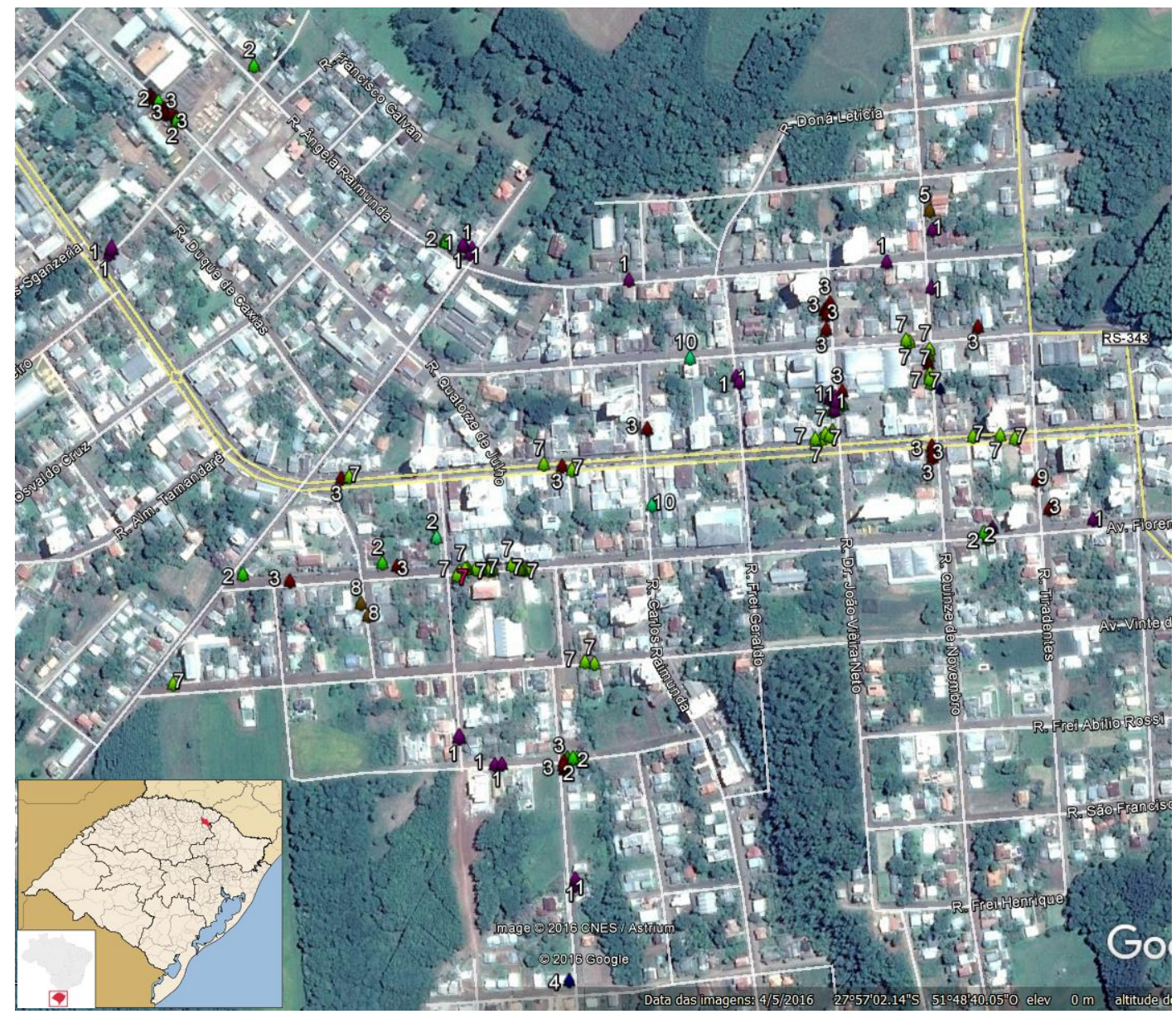

Nota: (1) Cinnamomum burmannii (Nees \& Th. Nees) Nees ex Blume; (2) Melia azedarach L.; (3) Ligustro lucidum; (4) Pinus sp. , (5) Acacia podalyrifolia, (6) Terminalia catappa L., (7) Cupresses lusitânica, (8) Persea americana Mill., (9) Psidium guajava L. e (10) Syzygium cuminni

Das espécies mais abundantes, segundo Backes e Irgang (2004), a Lagerstroemia indica é originária da Ásia e Oceania e parece ser ideal para o plantio em calçadas, pois é considerada ornamental pelo colorido de suas flores, por possuir uma copa globosa sobre um fuste reto. Por ser um espécime descrito como rústico, suporta muito bem o clima e solo urbano. Mesmo sendo uma espécie exótica, não é capaz de realizar invasão biológica e por isso não apresentam riscos à diversidade nativa (BLUM et al. 2008).

Já o Ligustrum lucidum, Hoppen et al. (2014) descrevem que o espécime apresenta grande quantidade de frutos com largo período de frutificação, podendo assim competir com as 
espécies nativas. Os mesmos autores ainda salientam que a espécie é nativa da China e Coréia e foi introduzida por fins ornamentais para compor a arborização urbana, sendo muito comum nas áreas urbanas, apesar de não ter relevância paisagística, danificar ruas e calçadas e ainda manter contato com a fiação elétrica. Destaca-se que além disso, os frutos são tóxicos para pessoas e a ingestão pode causar sintomas como náusea, dores de cabeça, dores abdominais, vômitos, diarréia, pressão baixa e hipotermia.

Estudos sobre arborização em zona urbana em outras cidades brasileiras vem demostrando o predomínio das espécies exóticas sobre as nativas (BRITO et al., 2015; BOENI; SILVEIRA, 2011).

As principais causas diretas da perda de biodiversidade podem ser apresentadas de forma resumida como: a conversão de hábitats naturais em atividades humanas, o avanço da fronteira agrícola; as mudanças climáticas; as espécies exóticas invasoras; a superexploração; e a poluição (LEÃO et al. 2011). Destacando-se as espécies exóticas invasoras, fica exposto o poder público deve "impedir que sejam introduzidas e deve controlar ou erradicar espécies exóticas que ameacem ecossistemas, hábitats ou espécies" (art. 8h da CDB, 1992). A mensagem desse artigo foi transposta para a Lei de Crimes Ambientais (art. 61 da Lei Federal n 9.605/98), que considera crime ambiental a disseminação de doenças ou pragas ou espécies que possam causar dano à agricultura, à pecuária, à fauna, à flora ou aos ecossistemas (BRASIL, 1998).

Cabe ao poder público municipal criar mecanismos de planejamento para reduzir o desequilíbrio existente entre a quantidade de espécimes exóticas e nativas, sugere-se que os espécimes exóticos sejam gradativamente substituídos por nativos, tendo em vista os benefícios proporcionados pela flora nativa (ALMEIDA; NETO, 2010; BARROS et al., 2010; KRAMER; KRUPEK, 2012; ROMANI et al., 2012; SALVI et al., 2011; SOUZA et al., 2011), uma vez que estas contribuem para o equilíbrio do ambiente local e servem de alimento para a avifauna.

\section{CONCLUSÃO}

A quantidade de espécies exóticas nas ruas avaliadas apresentou maior frequência que as espécies nativas.

Faz-se necessária uma abordagem diferenciada no planejamento arbóreo-urbano de Sananduva/RS, com base em critérios técnico-científicos para o estabelecimento de uma arborização urbana voltada ao emprego de um maior número de espécies nativas da região juntamente com a substituição gradativa dos indivíduos exóticos, no propósito de beneficiar a biodiversidade e ecossistemas naturais. 


\section{AGRADECIMENTOS}

Especial agradecimento à instituição que financiou o trabalho, disponibilizando bolsas de extensão: Pró-Reitoria de Extensão da Universidade Estadual do Rio Grande do Sul - ProEx

\section{REFERÊNCIAS}

ALMEIDA, D.N.; NETO, R.M.R. Análise da arborização urbana de duas cidades da região norte do estado de Mato Grosso. Revista Árvore, Viçosa-MG, v.34, n.5, p.899-906, 2010.

ANDRADE, T. O. Inventário e análise da arborização viária da estância turística de Campos do Jordão, SP. São Paulo, 2002. 112p. Dissertação (Mestrado) - Escola Superior de Agricultura “Luiz de Queiroz", Universidade de São Paulo, Piracicaba-SP, 2002.

BACKES, P.; IRGANG, B. Árvores cultivadas no sul do Brasil: Guia de identificação e interesse paisagístico das principais espécies exóticas. Porto Alegre: Palotti, 2004. 204 p.

BARROS, E.F.S.; GUILHERME, F.A.G.; CARVALHO, R.S. Arborização urbana em quadras de diferentes padrões construtivos na cidade de Jataí. Revista Árvore, Viçosa-MG, v.34, n.2, p.287295, 2010.

BLUM, C. T.; BORGO, M.; SAMPAIO, A. C. F. Espécies exóticas invasoras na arborização de vias públicas de Maringá - PR. Revista da Sociedade Brasileira de Arborização Urbana, Piracicaba-SP, v.3, n.2, jun. 2008, p.78-97.

BRITO, L. de.; HOSSOMI, S. T.; OLIVEIRA, L. W. de. Espécies exóticas na arborização viária do município de Rancharia - SP. Cidades Verdes, Tupã-SP, v.03, n.06, p. 69-74, 2015

BOENI, B. O.; SILVEIRA, D. Diagnóstico da arborização urbana em bairro do município de Porto Alegre - RS, BRASIL. Revista da Sociedade Brasileira de Arborização Urbana, PiracicabaSP, v. 6, n.3, p. 189-206, 2011.

CDB. Convenção da diversidade biológica, 1992.

DALL AQUA, M., MÜLLER, N. T. G. Diagnóstico da arborização urbana de duas vias na cidade de Santa Rosa - RS. Revista da Sociedade Brasileira de Arborização Urbana, PiracicabaSP, v. 9, n. 3, p. 141-155, 2014.

DORIGON, E. B.; PAGLIARI, S. C. Arborização urbana: importância das espécies adequadas. Unoesc \& Ciência-ACET, Joaçaba-SC, v. 4, n. 2, p. 139-148, 2013.

HOPPEN, M. I.; DIVENSI, H. F.; RIBEIRO, R. F.; CAXAMBÚ, M. G. Espécies exóticas na arborização de vias públicas no município de Farol, PR, Brasil. Revista da Sociedade Brasileira de Arborização Urbana, Piracicaba-SP, v. 9, n. 3, p. 173-186, 2014.

HORUS INSTITUT Base de dados nacional de espécies exóticas invasoras I3N Brasil, Instituto Hórus de Desenvolvimento e Conservação Ambiental, Florianópolis - SC. $<$ http://i3n.institutohorus.org.br/www/?p=NzsycSVtMGE2OWQIJENYEhMBUAVUBBYZHEolb2p veThtaw\%3D\%3D> Acesso em 16 mar. 2017. 
INSTITUTO AMBIENTAL DO PARANÁ. PORTARIA, IAP página o 814. Disponível em <http://www.iap.pr.gov.br/pagina-814.html> Acesso em: 16 mar. 2017

INSTITUTO BRASILEIRO DE GEOGRAFIA E ESTATÍSTICA (IBGE). Censo Demográfico 2010. Disponível em: <http://cod.ibge.gov.br/61N> Acesso em: 8 nov. 2012

KRAMER, J.A.; KRUPEK, R.A. Caracterização florística e ecológica da arborização de Praças Públicas do Município de Guarapuava, PR. Revista Árvore, Viçosa-MG, v.36, n.4, p.647-658, 2012.

LEÃO, T. C. C.; ALMEIDA, W. R.; DECHOUM, M.; ZILLER, S. R. Espécies Exóticas Invasoras no Nordeste do Brasil: Contextualização, Manejo e Políticas Públicas. Recife: Cepan, 2011.

MATOS, E.; QUEIROZ, L.P. de. Árvores para cidades. Salvador: Ministério Público da Bahia: Solisluna, 2009. 340p.

MELO, R. R.; LIRA FILHO, J. A.; RODOLFO JÚNIOR, F. Diagnóstico qualitativo e quantitativo da arborização urbana no bairro Bivar Olinto, Patos, Paraíba. Revista da Sociedade Brasileira de Arborização Urbana, Piracicaba-SP, v. 2, n. 1, p. 64-80, 2007.

MOTTER, N; MULLER, N. G. Diagnóstico da arborização urbana no município de Tuparendi RS. Revista da Sociedade Brasileira de Arborização Urbana, Piracicaba-SP, v. 7, n. 4, p. 27 36, 2012.

RIBEIRO, F. A. B. S. Arborização urbana em Uberlândia: Percepção da população. Revista da Católica, Uberlândia-MG, v. 1, n. 1, p. 224-237, 2009.

ROMANI, G.N.; GIMENES, R.; SILVA, M.T.; PIVETTA, K.F.L.; BATISTA, G.S. Análise qualiquantitativa da arborização na Praça XV de Novembro em Ribeirão Preto - SP, BRASIL. Revista Árvore, Viçosa-MG, v.36, n.3, p.479-487, 2012.

SALVI, L.T.; HARDT, L.P.A.; ROVEDDER, C.E.; FONTANA, C.S. Arborização ao longo de ruas túneis verdes em Porto Alegre, RS, BRASIL: avaliação quantitativa e qualitativa. Revista Árvore, Viçosa-MG, v.35, n.2, p.233-243, 2011.

SAMPAIO, A. C. F.; ECKER, A. E. do A.; MARANGONI, C. J.; FIORESE, L. M. R.; SORDI, E.A. Espécies exóticas invasoras na arborização de vias públicas de três bairros de Campo Mourão - PR. Campo Digit@I, Campo Mourão-PR, v.6, n.1, p.31-43, jan/jul., 2011.

SOUZA, A.L.; FERREIRA, R.A.; MELLO, A.A.; PLÁCIDO, D.R.; SANTOS, C.Z.A.; GRAÇA, D.A.S.G.; JÚNIOR, P.P.A.; BARRETTO, S.S.B.; DANTAS, J.D.M.; PAULA, J.W.A.; SILVA, T.L.; GOMES, L.P.S. Diagnóstico quantitativo e qualitativo da arborização das praças de Aracaju, SE. Revista Árvore, Viçosa-MG, v.35, n.6, p.1253-1263, 2011. 